\title{
QUESTÕES DE VARIAÇÃO NO CONTEXTO ESCOLAR
}

Maria Teresa Tedesco Vilardo Abreu (UERJ)

Resumo: Este artigo tem por objetivo discutir a questão da avaliação no contexto da sala de aula básica. Imputa-se como fundamental o ensino de língua materna na perspectiva variacionista porque, considerando a visão funcionalista da língua, especificamente a Teoria da Variação, entende-se que a língua é heterogênea. Há de se pensar, entretanto, em dois pontos importantes: (i) que abordagens variacionistas têm sido feitas na escola. (ii) que concepção, de fato, vige, em relação à variação na visão dos docentes. Para tanto, pretende-se apresentar, em primeiro plano, a teoria da variação, postulada por Labov; a seguir, pretendese apresentar a perspectiva de variação prevalente na matriz de língua portuguesa concernentes à avaliação de larga escala, o SAEB/PROVA BRASIL. Por fim, pretende-se verificar o respectivo fenômeno em textos produzidos por estudantes da escola básica, a fim de propor caminhos metodológicos alternativos para o ensino de língua materna.

Palavras-chave: Variação; Escola Básica; Habilidades; Ensino de Língua Portuguesa.

Abstract: This article aims to discuss the issue of assessment in the context of the basic classroom. The teaching of the mother tongue is considered as fundamental in the variationist perspective because, considering the functionalist view of the language, specifically the Variation Theory, it is understood that the language is heterogeneous. There are, however, two important points to be considered: (i) what variationist approaches have been made at school. (ii) what conception, in fact, applies in relation to the variation in the teachers' view. Therefore, it is intended to present, in the foreground, the theory of variation, postulated by Labov; next, we intend to present the perspective of variation prevalent in the matrix of Portuguese language concerning the large scale evaluation, SAEB/PROVA BRASIL. Finally, we intend to verify the respective phenomenon in texts produced by students of the basic school, in order to propose alternative methodological paths for mother language teaching.

Keywords: Variation; Basic School; Skills; Portuguese Language Teaching. 


\section{INTRODUÇÃO}

Não se pode, na atualidade, negar o caráter social da língua, contribuição ímpar concernente aos avanços das pesquisas linguísticas. Por isso, quando se pensa no fenômeno da variação, pensamos na Sociolinguística, ou seja, a língua na sociedade. Distanciamo-nos totalmente da concepção de língua como uma estrutura formatada, pronta e acabada; tomamos como ponto de partida teórico o conceito de língua como algo suscetível à mudança e à variação. Esse conceito afirma em nós, estudiosos da língua, a premissa de que os usuários de uma língua sofrem influências na forma como falam, de onde falam e na maneira como usam a língua nas diferentes situações de comunicação. Para a Sociolinguística, é essencial entendermos a língua em uso, observarmos as diferentes formas de falar, quem são os falantes, o que os influencia e as linguagens em uso à sua volta. Por isso, trata-

se de um estudo da relação entre a língua que falamos e a sociedade em que vivemos.

A língua é compreendida como uma fonte geral e universal que pode ser estudada e analisada cientificamente, sendo a variação, seu objeto de estudo. Para essa ciência, as línguas são dinâmicas, têm suas peculiaridades e se agregam heterogeneamente. A Sociolinguística postula a importância 
social da linguagem, estudando as diferentes manifestações não só em comunidades maiores, mas também nos pequenos grupos socioculturais. Além disso, há interesse pelo contato entre as línguas, pelas questões relativas ao surgimento e extinção linguística, pelo multilinguismo, pela mudança em geral.

Diante desta perspectiva teórica, inquiro-me se esta perspectiva de língua, ou melhor, se este conceito de língua vige na escola básica e, mais do que isso, vige no entendimento dos docentes de língua.

Para desenvolver essa perspectiva, proponho-me a apresentar de forma sucinta a teoria da variação postulada por Labov. A seguir, discuto o tópico variação na Matriz de Referência do SAEB / PROVA BRASIL. Objetiva-se analisar o fenômeno da variação na perspectiva da escola e da formação dos docentes, desejando-se ampliar (em muito) o escopo da discussão para a sala de aula.

\section{ALGUMAS CONSIDERAÇÕES SOBRE A TEORIA DA VARIAÇÃO}

A Teoria da Variação é um modelo teórico-metodológico cujo objeto de estudos é a língua em uso pelo falante numa dada situação de comunicação real, possibilitando o estudo de qualquer fenômeno linguístico variável. Trata-se, na 
verdade, de um estudo que procura identificar os fatores condicionantes da escolha entre as formas alternantes de dizer. Esses fatores (ou variáveis) podem ser internos ao sistema linguístico ou externo a esse sistema, como por exemplo, o gênero, o nível social, a escolaridade, a idade, dentre outros fatores externos à língua. Os fatores estão, sempre, relacionados ao uso do fenômeno em estudo dentro de uma situação real de comunicação.

Os estudos variacionistas foram iniciados por Labov, precursor deste modelo teórico-metodológico, centrados a princípio nos fenômenos fonéticos e morfo-fonológico. $\mathrm{O}$ ponto fundamental é o caráter social da linguagem, opondo-se ao caráter inato, postulado por Chomsky, por exemplo. Esses estudos, na atualidade, ampliaram-se para a perspectiva da variação em fenômenos sintático-discursivos, aspecto muito importante para o avanço dos estudos sociolinguísticos. Neste sentido, a teoria impõe a necessidade de estudar os fenômenos sintáticos dentro de um contexto discursivo e não em orações isoladas, ratificando a importância do contexto para o projeto de dizer do texto.

Além da premissa básica do caráter social da linguagem, outra premissa da teoria é a equivalência de significado das formas variantes, ou seja, das formas alternantes, 
condicionadas aos fatores linguísticos e não linguísticos de uma dada ocorrência da língua. A identidade de contextos, por conseguinte, é fundamental para que duas ou mais variantes possam ser atribuídas à mesma variável, ou seja, para a existência de uma ou mais formas alternantes.

Como observa Mollica (2003, p.10), "ela parte do pressuposto de que toda variação é motivada, isto é, controlada por fatores de maneira tal que a heterogeneidade se delineia sistemática e previsível". Por isso, não coadunamos com a ideia de existência de um caos linguísticos ou uma língua eivada de exceções. Os fenômenos linguísticos são vários, variáveis, porém previsíveis e regulares. A Teoria da Variação se dedica à língua em seu contexto sociocultural, pois se constrói a partir da diversidade, da heterogeneidade que caracteriza uma dada língua. Concretiza nas escolhas dos usos linguísticos que o falante faz, motivada por seus objetivos sem dúvida, mas também pelos fatores externos ao sistema linguístico, quase sempre, motivados por esses, bem como os fatores internos da língua.

É muito importante, para o entendimento do fato linguístico, que seja calculada a interferência que cada fator interno ou externo ao sistema linguístico possui para que uma ou outra forma alternante aconteça. Isto implica em dizer 
que a análise sociolinguística procura constituir a relação entre o processo de variação que se analisa na língua em um determinado período (sincrônico), de acordo com os fatores que Ihe propiciam as mudanças em dada comunidade, em um dado tempo ou ao longo do tempo (diacrônico).

Em toda sua relevância, a proposta teórica- metodológica de Labov não se esgota na análise das estruturas da língua, mas se apresenta na variação condicionada por fatores de ordem social, que podem funcionar como marca de identificação na comunidade em que ocorrem. Nas palavras do próprio Labov (2006 [1968], p.247):

Tudo parece comprovar a hipótese de que os falantes da classe média baixa mantêm uma forte tendência ao sentimento de insegurança linguística e, em função disso, procuram adotar as formas de prestígio utilizadas pelos membros mais jovens da classe alta. Essa insegurança se manifesta na grande amplitude de variação estilística da classe média baixa, na grande flutuação dentro de um dado contexto estilístico, em seu esforço consciente de correção e em suas atitudes fortemente negativas com referência aos padrões de linguagem que herdaram.

A fim de ilustrar o caráter discursivo a que nos referimos, propomos a comparação de dois trechos de narrativas produzidas por um mesmo estudante em um mesmo ponto 
da história narrada, material utilizado em pesquisa realizada na Universidade do Estado do Rio de Janeiro (UERJ), a fim de verificar os elementos conjuntivos Aí e $E$, as orações sem marca inicial e as iniciadas por outros elementos conjuntivos, tratados como variantes, visto que obedecem às duas premissas básicas da teoria da variação:

(I) São formas alternantes de ligação que não afetam o significado;

(II) Podem ocorrer em um mesmo contexto.

Exemplo 1:

Ele foge...

tenta pegar ele de de surpresa

e acaba caindo no chão

se machuca...

a enfermeira... socorre... o médico...

\section{AÍ O FILHO VAI EMBORA... SEM O CHECK UP... DEPOIS DE TER APRONTADO TUDO... QUE APRONTOU...}

Trata de um excerto de uma narrativa oral em que o produtor do texto relata a cena de um paciente, uma criança pequena que está fugindo do médico, em um atendimento em seu consultório. $O$ médico, ao tentar alcançar o pequeno paciente, cai da cadeira e o menino vai embora sem ser medicado, ou seja, sem fazer o check-up que precisava fazer naquela consulta. Na pesquisa, solicitou-se que os 
estudantes de diferentes escolaridades relatassem a história infantil projetada e, em outro momento, contassem, por escrito, a mesma história. Vejamos o excerto escrito do mesmo estudante.

Exemplo 2:

Só que não consegue, pois o menino se solta da mãe e sai correndo.

Este desiste de tentar convencê-lo

De examiná-lo, Ou mesmo fazê-lo forçadamente, E volta para casa com seu filho Sem que ele tenha feito sequer um exame.

Como já dito, trata-se de dois processos narrativos de um mesmo estudante do nono ano de escolaridade, do gênero masculino. O que se atestou com essa pesquisa são dois fatos linguísticos muito interessantes e por que não dizer importantes:

(I) Nas narrativas orais, há frequente incidência do uso do elemento conjuntivo aí como forma de ligação entre as partes do texto;

(II) Nas narrativas escritas, o elemento conjuntivo aí deixa de ser usado. Outros elementos são incorporados ao discurso, a exemplo dos elementos conjuntivos E, Então, Quando, de acordo com o contexto semântico-discursivo. 
Pode-se observar que, nos exemplos 1 e 2, a mesma cena é contada e no mesmo ponto da narrativa, aí, no registro oral, é utilizado como um sequenciador, conclusivo; na escrita este aí é substituído por $E$, mantendo o sentido. Os resultados da pesquisa realizada apontam para uma forte intervenção da escola no uso do elemento conjuntivo, típico da oralidade.

Numa perspectiva sociolinguística, há de se entender os dois usos como ocorrências possíveis na língua. Existentes e não estigmatizantes. Cabe à escola, aliada ao processo descritivo de uma língua viva, dinâmica e heterogênea mostrar as possibilidades de uso, os contextos em que podem / devem ser usadas as diferentes formas de dizer da língua, fazendo com que o estudante entenda o processo de construção da língua em sua pluridiversidade.

Sem dúvida. A variação linguística vem sendo estudada na escola básica. Acredito, entretanto, que seu escopo tem sido reduzido, sobretudo para a diversidade regional. Evidente que se trata de uma perspectiva importante, diria, uma tomada de consciência sobre a existência de diferentes falares brasileiros. Postula, entretanto, que a perspectiva variacionista tem de ser concebida como uma condição da língua, como uma condição de sua estrutura, que traz um 
novo olhar para a sua gramática. Vige na abordagem da língua em sala de aula da escola básica não só um entendimento estrutural dos fenômenos da língua, mas também um olhar preconceituoso em relação aos possíveis usos dentro dos diferentes escopos linguísticos.

O primeiro olhar de afastamento ocorre exatamente ente as duas modalidades da língua: a oral e a escrita. Como professores de língua materna, sabe-se que os estudantes, ao chegarem à escola, trazem em seu repertório linguístico um total domínio da língua oral. Porque vão aprender a língua escrita na escola, não a dominam e trazem para a escrita as marcas da oralidade. Em uma postura sociolinguística, em uma concepção variacionista, temos os docentes que discutir com nossos estudantes estas formas alternantes, levando o estudante a entender não só as possibilidades de uso, mas as condições de uso de uma dada forma, a fim de que seja capaz de (re)construir suas perspectivas linguísticas.

Os dois excertos (Exemplos 1 e 2) exemplificam as caraterísticas apontadas por Chafe, ao diferenciar os processos escrita/fala. A escrita é um processo mais elaborado e integrado, enquanto a fala é uma produção mais fragmentada, produzida de forma menos elaborada porque abriga uma contextualização ampla, por parecer que o falante 
pressupõe que há informações partilhadas entre os dois interlocutores ou informações armazenadas na consciência de seu interlocutor. Há um acordo tácito em relação aos conhecimentos partilhados, o que leva o produtor a calcular o que seu interlocutor sabe sobre dada situação.

Em contrapartida, vê-se claramente uma integração das informações, a exemplo de (Este desiste de tentar convencêlo / De examiná-lo, / Ou mesmo fazê-lo forçadamente [...]) quando novas formas são instauradas no discurso, ao usar a subordinada, imputando à oração um aspecto maior de ligação, de coesão. Esse mesmo falante, na narrativa oral, utiliza orações coordenadas (e acaba caindo no chão/ se machuca... / a enfermeira... socorre... o médico [...]), o que pode dar a sensação de um texto mais fragmentado. Há de se entender que não existe erro, mas escolhas calculadas pelos interlocutores que atendam aos seus propósitos comunicativos, dentro de seu repertório linguístico.

Neste sentido, a função da escola é precípua ao ampliar o repertório linguístico dos estudantes para a heterogeneidade da língua e suas possibilidades variacionistas, a fim de desenvolver sal consciência de uso, sem querer aferir o que é certo ou errado nas escolhas do falante, mas o que é possível na língua, quando é possível e em que contexto (s) pode ser utilizado. Esta tomada de consciência é fundamental. 


\section{O QUE DIZ A MATRIZ DE REFERÊNCIA SOBRE VARIAÇÃO}

Os estudos linguísticos, principalmente, a sociolinguística vem imputando ao currículo escolar uma grande contribuição. Em se tratando de matrizes de referência em Língua Portuguesa, a variação está presente, forçando o olhar para a heterogeneidade da língua.

Vejamos a Matriz de Referência do SAEB:

\section{VARIAÇÃO LINGUÍSTICA}

Identificar as marcas linguísticas que evidenciam o locutor e o interlocutor de um texto.

Matriz de Referência do SAEB- INEP/ MEC - Brasil ${ }^{1}$

Para os três anos finais avaliados - 50 ano, 9 음 ano do Ensino Básico e o 3o ano do Ensino Médio, o descritor é o mesmo: identificar as marcas de linguagem afeitas aos interlocutores. De acordo com o material de treinamento de Professores do Estado do Paraná, o tópico de variação linguística refere-se

Às inúmeras manifestações e possibilidades da fala. No domínio do lar, as pessoas exercem papéis sociais de pai, mãe, filho, avó, tio. Quando observamos um diálogo entre mãe e filho, por exemplo, verificamos características linguísticas que marcam ambos os papéis. As diferenças mais marcantes são intergeracionais (geração mais velha/geração mais nova).

1 Fonte: Elaborado pela Daeb/Inep a partir do Saeb/Inep (2002) 
A percepção da variação linguística é essencial para a conscientização lingüística do aluno, permitindo que o estudante construa uma postura não preconceituosa em relação a usos linguísticos distintos dos seus. É importante, além dessa percepção, compreender as razões dos diferentes usos, a utilização da linguagem formal, a informal, a técnica ou as linguagens relacionadas aos falantes, como por exemplo, a linguagem dos adolescentes, das pessoas mais velhas etc. É necessário transmitirmos ao aluno a noção do valor social que é atribuído a essas variações, sem, no entanto, permitir que ele desvalorize sua realidade ou a de outros.

Cadernos de Atividades do SEP- Governo do Paraná, 2009

Trata-se, sem dúvida, de uma importante habilidade que leva os estudantes a conhecerem não só os recursos linguísticos utilizados, mas, além disso, as escolhas realizadas a partir da função discursiva que cada um exerce, atrelado ao seu propósito comunicativo. Observa-se, entretanto, considerando a perspectiva laboviana como a habilidade está restrita a um pequeno viés do que se entende sobre variação; a própria explicação sobre o descritor, ainda que tenha tentado ser abrangente e estar em consonância com a teoria, limita-se a uma citação de possibilidades, ressaltando, apenas, a questão do preconceito, sem atinar para a questão dos usos e das possibilidades. Considero 
limitadora a explicação, sobretudo, por se tratar de material de formação do(a) professor(a).

A seguir, apresento dois itens de leitura que avaliam este descritor de habilidade:

Leia o texto abaixo:

\section{O socorro ${ }^{2}$}

Ele foi cavando, cavando, cavando, pois, sua profissão - coveiro - era cavar. Mas, de repente, na distração do ofício que amava, percebeu que cavara demais. Tentou sair. Gritou. Ninguém atendeu. Gritou mais forte. Ninguém veio. Enrouqueceu de gritar, cansou de esbravejar, desistiu com a noite. Sentou-se no fundo da cova, desesperado. A noite chegou, subiu, fez-se o silêncio das horas tardias. Bateu o frio da madrugada e, na noite escura, não se ouvia um som humano, embora o cemitério estivesse cheio dos pipilos e coaxares naturais dos matos. Só pouco depois da meia-noite é que lá vieram uns passos. Deitado no fundo da cova o coveiro gritou. Os passos se aproximaram. Uma cabeça ébria apareceu lá em cima, perguntou o que havia: "O que é que há?" O coveiro então gritou, desesperado: "Tire-me daqui, por favor. Estou com um frio terrível!". "Mas, coitado!" - condoeu-se o bêbado - "Tem toda razão de estar com frio. Alguém tirou a terra de cima de você, meu pobre mortinho!" E, pegando a pá, encheu-a de terra e pôs-se a cobri-lo cuidadosamente.

2 Millôr Fernandes Fonte: http://www.consciencia.net/2004/mes/03/millor-socorro.html Acesso em 15.Jun2008 
"O que é que há?" Quem fez essa pergunta foi:
a) $\mathrm{O}$ mortinho.
b) A cabeça ébria.
c) O coveiro.
d) $\mathrm{O}$ narrador.

Leia o texto:

O pulo

A Onça encontrou o Gato e pediu:

- Amigo Gato, você me ensina a pular?

O Gato ficou muito desconfiado, mas concordou. Nas últimas aulas, a Onça pulava com rapidez e agilidade, parecia um gato gigante.

- Você é um professor maravilhoso, amigo Gato! Dizia a Onça, agradando[...].

Fonte: Francisco Marques. Contos e lendas populares.

Nessa fábula, quem disse que "a onça parecia um gato gigante" foi o
a) Professor
b) Gato
c) Leitor
d) Narrador

Em ambos os itens, trata-se de uma mera identificação de fala e produtor da fala, deixando de lado a discussão sobre a função e o uso da língua. Chega-se ao absurdo de no item 2 ter como uma das alternativas o Leitor, o que não faz qualquer sentido, considerando-se o texto, seu contexto 
que inclui os atores, personagens do texto. Há a inserção da teoria linguística, mas os itens mantêm a visão estrutural da língua. Em se tratando de uma prova de leitura, afirmo de forma categórica, o enviesamento de objetivos tanto para o desenvolvimento da habilidade dos discentes como a formação tão necessária dos docentes.

\section{À GUISA DE CONCLUSÃO}

Ainda há muito o que fazer para que as teorias linguísticas, de fato, alcancem o chão da escola. Se, por um lado, fica constatada a importância dos estudos variacionistas para o entendimento das línguas, se fica constatada a heterogeneidade como condição precípua da língua, fica constatada, por outro lado, a necessidade de se ampliar à elevada potência a disseminação do que vamos denominar aplicação em sala de aula, propiciando, de fato, o desenvolvimento das habilidades linguísticas dos estudantes. Como falantes, esses meninos e meninas - esses cidadãos - ainda não entendem as diferenças entre os processos de fala e escrita. Por isso, tentam transferir os comportamentos linguísticos que são naturais na fala, pressupondo, por exemplo uma contextualização que na escrita não existe.

Por fim, mas não menos importante, largar o universo de conhecimentos dos professores é a condição única e 
necessária para que o desenvolvimento das habilidades de leitura e o conhecimento da língua pelos estudantes seja, de fato, em nossas escolas, ou melhor, em nossa sociedade, em breve tempo.

A contribuição deste artigo é estritamente fazer pensar sobre as limitações existentes em nosso fazer pedagógico, vigente nas salas de aulas brasileiras, a despeito de todo o avanço das pesquisas em linguística e em língua materna.

\section{REFERÊNCIAS}

ADAM, J. M. (2008). A linguística Textual: Introdução à Análise Textual dos Discursos. São Paulo, Cortez.

ADAM, J. M. (1987). Textos: Tipos e Protótipos. São Paulo: Contexto.

CHAFE, Wallace (1980). "The development of consciousness in the production of a narrative". In: . The pear stories: Cognitive, cultural and linguistics aspects of narrative production. New Jersey, Ablex Publishing Company. p.9-50

LABOV, W. ([1972] 2008). Padrões sociolinguísticos. São Paulo: Parábola. (1978) "Where does the Linguistic variable stop? A response to Beatriz Lavandera". Sociolinguistic Working Papers. 44, p.43-88. (2003) "Some sociolinguistic principles". In: PAULSTON, Cristina Bratt; TUCKER, G. Richard (Eds.). Sociolinguistics: the essential readings. Oxford: Blackwell. p.235-250.

Matriz de Referência do SAEB - INEP/ MEC GBRASIL (2002).

MOLLICA, M. C.; BRAGA, M. L. (Orgs.) (2010). Introdução a Sociolinguística: o tratamento da variação. 4.ed. São Paulo.

MOLLICA. M. C. (2003). "Relativas em tempo real no português brasileiro contemporâneo". In PAIVA, M. C.; DUARTE, M. E. L. (Orgs.). Mudança linguística em tempo real. Rio de Janeiro: Contra Capa. 
Maria Teresa Tedesco Vilardo Abreu é Pós-Doutora em Linguística pela Universidade de Colônia, Alemanha (2017), Doutora pela Universidade Federal do Rio de Janeiro (2002), Mestre em Linguística pela Universidade Federal do Rio de Janeiro (1992). Atua como docente na UERJ, desde 1985, no Colégio de Aplicação Fernando Rodrigues da Silveira; desde 2003, no Instituto de Letras, tanto nos cursos de Graduação quanto nos de Pós-Graduação stricto sensu. Desde 2014 é Professora Associada da Universidade do Estado do Rio de Janeiro. Tem experiência na área de Letras, com ênfase em Língua Portuguesa, atuando principalmente nos seguintes temas: Ensino de Língua Portuguesa, Uso e descrição da Língua Portuguesa, Avaliações em Larga Escala. Tem experiência em diferentes Bancas Examinadoras, em processos seletivos e redação. Tem vários artigos e livros publicados.

E-mail: teresatedesco@uol.com.br 